\title{
Carreira militante, inserção profissional e exercício do jornalismo no Rio Grande do Sul
}

Fernanda Rio Petrarca*

\section{Introdução}

C ste artigo tem como objetivo apresentar alguns resultados de Zum trabalho mais geral sobre as condições sociais de ingresso e ascensão profissional no Jornalismo. Trata-se, mais especificamente, de mostrar a relação entre os usos de recursos obtidos por meio da militância política e do engajamento associativo para inserção e ascensão no Jornalismo. Ao mesmo tempo, pretende-se discutir alguns problemas analíticos no estudo da relação entre exercício profissional, militância e formas de atuação política ${ }^{1}$.

Desse modo, o material empírico que serve de base é constituído por uma pesquisa do conjunto dos jornalistas que ocupam posições dirigentes em diversos espaços de atuação profissional ${ }^{2}$ (como jornais, emissoras de rádio, canais de televisão, assessoria de imprensa, universidade, entidades associativas e de representação profissional). Em tal pesquisa, a capacidade de mobilizar diferentes

* Doutora em Sociologia pela Universidade Federal do Rio Grande do Sul e professora do Departamento de Sociologia e Política da Universidade Federal de Pelotas. Endereço eletrônico: f.petrarca@uol.com.br.

1 Este artigo é uma versão modificada do trabalho originalmente apresentado no evento "Jornadas Internacionales de Estudio sobre Militantismo", ocorrido em Santiago do Chile em 2007. Agradeço aos comentários e sugestões de Ivan Bruneau e Bernard Pudal, debatedores da mesa em que o trabalho foi apresentado.

2 Esta pesquisa foi realizada para conclusão de uma tese de doutorado, intitulada "O Jornalismo como profissão: recursos sociais, titulação acadêmica e inserção profissional dos jornalistas no RS”, realizada no Programa de Pós-Graduação em Sociologia da UFRGS. 
inserções e reconverter recursos provenientes de espaços sociais os mais diversos apresentou-se como uma garantia de "sucesso" no Jornalismo. Dentre os recursos mobilizados, estão aqueles proporcionados pelas origens sociais elevadas, os obtidos no interior das redações jornalísticas e aqueles acumulados pela experiência em movimentos sociais, na militância estudantil, na atuação em partidos políticos e na inserção em entidades associativas ${ }^{3}$. O presente artigo, no entanto, circunscreve aos jornalistas que mobilizaram recursos oriundos da atuação militante e política, portanto jornalistas cuja característica principal é o alto grau de capital militante e político. Essa restrição do universo empírico permite a discussão com problemas relativos às relações entre exercício profissional e carreira militante.

A bibliografia pertinente tem destacado nas análises sobre o espaço da militância, da política e dos universos profissionais, a organização e a dinâmica interna destes espaços, por um lado desenvolvendo um conjunto vasto de trabalhos na linha dos processos de engajamento e mobilização coletiva, inserindo as discussões na sociologia dos movimentos sociais e da ação coletiva. Por outro lado, dedicando-se aos estudos da formação de grupos profissionais e sua dinâmica interna de organização e funcionamento, inserindo, desse modo, as discussões na chamada "sociologia das profissões". Entretanto, a relação entre profissão, política e militância tem tornadose, recentemente, objeto de um conjunto de estudos e pesquisas nas ciências sociais. A literatura atual tem salientado tanto a profissionalização da militância e da política, como as retribuições da

3 Ao total somaram-se 46 entrevistas e foram definidos três grandes padrões de associação e reconversão de recursos diversos em posições profissionais. Um primeiro padrão consiste naqueles jornalistas que tem como principal base de recursos os de origem social elevada, correspondendo a um total de 11 casos dos 46 analisados. Os principais postos ocupados são, sobretudo, os de editores, chefes e diretores de redação. Um segundo padrão consiste na combinação entre os recursos obtidos por meio do intenso investimento nas redações jornalísticas e aqueles proporcionados pelo espaço escolar, correspondendo a um total de 15 casos. Destacam-se, nesse caso, postos em assessoria de imprensa e redações jornalísticas. E por fim, a modalidade que interessa neste texto, que representa aqueles jornalistas que tem como principal base de recursos aqueles obtidos por meio da militância política e partidária, correspondendo a 20 casos. As principais posições ocupadas por tais jornalistas estão mais diretamente relacionadas a universidade, entidades de classe e assessorias de imprensa públicas. 
atuação militante e as reconversões das competências profissionais (OFFERLÉ, 1996, 1999; SAWICKI, 1999). Neste texto interessa, particularmente, o problema da relação entre engajamento militante e reconversões profissionais.

Um dos aspectos persistentes no conjunto desses trabalhos tem sido o confronto entre as abordagens que focalizam as "afinidades" entre determinadas profissões e a política, como uma espécie de "osmose", já consagradas pela literatura (WEBER, 1982; DOGAN, 1999), e aquelas que têm se preocupado com as modalidades diversas de usos de qualificações e relações profissionais para formas também diversificadas de atuação e inserção na política (DULONG, 1996; WILLEMEZ, 1999; CORADINI, 2001). Os trabalhos de Dogan (1999), por exemplo, salientam a permeabilidade, a proximidade social e as afinidades entre o exercício de determinadas profissões e a política como uma espécie de continuidade encontrada, sobretudo, nas profissões que exigem o domínio da oratória e da prática discursiva. Esse é o caso do professorado, da advocacia e também do Jornalismo. Outro conjunto de pesquisas tem se preocupado com as associações diversas encontradas entre exercício profissional e a atuação política. O estudo de Dulong (1996) destaca-se, neste caso, por demonstrar de que forma certas competências profissionais, no caso aquelas adquiridas pelo exercício da economia, podem converter-se em competências políticas. De modo semelhante, as pesquisas de Gaxie (2005) e Gaxie e Offerlé (1985) têm destacado as retribuições e as recompensas diversas do militantismo e da ação coletiva, demonstrando de que forma a experiência militante e os investimentos em organizações coletivas oferecem ganhos e lucros facilitando, inclusive, a inserção no mercado de empregos. Os trabalhos de Coradini $(2001 ; 2006)$ também têm trazido contribuições relevantes para a forma como o exercício profissional e a atuação em associações e sindicatos profissionais tornam-se modalidades de entrada e trajeto político. Assim, o autor destaca a relação entre atuação profissional e representação de interesses baseados na condição profissional e sua conversão em representação política.

Tais pesquisas, ao mostrarem a imbricação entre estas esferas, trouxeram uma série de problemas e interrogações a serem analisados, permitindo repensar o tratamento dado até então às 
profissões e à mobilização social e ação coletiva. Um destes problemas é a forma como o exercício da militância e da participação política pode constituir-se em um recurso nas lutas profissionais por postos e posições e, ao mesmo tempo, em que medida a própria profissão pode tornar-se um recurso importante para agir na esfera da política e da militância. A forma como se configuram esses recursos (políticos e profissionais) em situações históricas particulares permite, muitas vezes, compreender os universos profissionais e as concepções de profissão em jogo.

No presente trabalho, no entanto, parte-se do princípio de que nas lutas profissionais por classificação e por acesso a certas posições os agentes comprometem os recursos que acumularam durante seu trajeto social e profissional e que resultam de sua origem social, formação escolar e inserção em outras esferas de atividade (BOLTANSKI, 1982; BOURDIEU, 1984; BOIEGOL \& DEZALAY, 1997). O que tem se observado, no caso do Jornalismo especialmente, é que o capital de relações é visto como imprescindível para o acesso à informação jornalística. O trabalho de Rieffel (1984) sobre os jornalistas franceses explicita a importância desse capital de relações para o acesso privilegiado a determinados universos e para o reconhecimento profissional. Assim, quanto maior o capital de relações de um jornalista, maior é a probabilidade de ascensão profissional, uma vez que as chances de obter informações em primeira mão elevam-se. Portanto, a extensão de suas relações transforma-se em competências profissionais e em uma forma de reconhecimento interno, constituindo-se em uma força dentro das redações jornalísticas. No caso do Brasil, observa-se que as possibilidades de utilização simultânea de vínculos de natureza diversa constituem um dos componentes básicos da "profissão de jornalista". Tais vínculos permitem fazer dessa atividade um espaço importante de mediação com outros espaços sociais. Contudo, esses usos simultâneos de recursos sociais variados não conduzem apenas a uma consagração interna em função de um amplo caderno de endereços, como destacado no caso francês, mas os efeitos principais disto são a ampliação e a diversificação da atuação jornalística em diferentes esferas de atividade (assessorias para partidos políticos, campanhas eleitorais, movimentos sociais, universidades, consultorias). Por conseguin- 
te, investir em um conjunto diversificado de contatos e vínculos não representa somente uma necessidade objetiva do Jornalismo; significa, além disso, investir em relações que podem resultar em novas posições profissionais em espaços diversificados deixando em aberto as possibilidades de intervenção jornalística ${ }^{4}$. Além disso, a necessidade de acumular diversos recursos sociais indica para concepções de Jornalismo que remetem a outros princípios de legitimação que não o exercício profissional strictu senso.

Uma das maneiras de dar conta empiricamente do trabalho de reconversão de recursos diversos para inserção e ascensão profissional consiste no confronto do elenco dos títulos que os agentes ostentam, levando em consideração, tanto aqueles estritamente escolares e profissionais, como aqueles obtidos pelos vínculos com outras esferas sociais. Para isso, a análise das trajetórias, entendida aqui como "uma série das posições sucessivamente ocupadas por um mesmo agente ou por um mesmo grupo de agentes em espaços sucessivos" (BOURDIEU, 1996, p.292), tornou-se um procedimento metodológico fundamental para apreender o conjunto de recursos acumulados. Nesta investigação interessou, particularmente, a relação entre recursos sociais e esferas de atuação, com objetivo de identificar de que forma as esferas em que os jornalistas estão inseridos possibilitam, enquanto espaços de sociabilidade, a acumulação de um conjunto de recursos que podem ser reconvertidos em recursos profissionais. Além disso, tornou-se igualmente relevante investigar de que forma a inserção em certas esferas sociais contribui para determinadas concepções de Jornalismo, uma vez que as esferas sociais são, ao mesmo tempo, espaços de interações concretas e uma estrutura de sentido (FILLIEULE, 2001; PASSY, 2005).

A investigação desses recursos permitiu construir um padrão de inserção e ascensão profissional que, por um lado, apresenta a militância política como a principal base de recursos profissionais que adquire importância por meio da associação com outros recursos pro-

4 A especificidade do Jornalismo brasileiro em comparação com outras situações nacionais, como a França, foi submetida a uma investigação mais ampla que incluiu os itinerários biográficos de diferentes gerações de jornalistas e que não se pode retomar aqui em função dos limites deste texto. 
venientes da inserção em várias esferas sociais (universidades, redação jornalística, associações profissionais). Por outro lado, apresenta uma forma peculiar de perceber a profissão de jornalista que associa "competência profissional" com inserção política. Consequientemente, a militância e a inserção na esfera política contribuem não só para acúmulo de recursos distintos, mas para uma maneira própria de ver o mundo e a própria atividade profissional ${ }^{5}$. Um dos elementos fundamentais que se destacou neste estudo é a forma peculiar de relacionar Jornalismo e militância para ocupação de posições jornalísticas e para ampliação das possibilidades de intervenção profissional.

\section{Modalidades de ingresso e ascensão no Jornalismo: o uso de recursos militantes}

O padrão de inserção e ascensão no Jornalismo apresentado neste texto consiste em trajetos que se caracterizam por posições ocupadas na militância estudantil, partidária e corporativa e que combinam o exercício do Jornalismo (em assessoria, na universidade, no Jornalismo diário) com outras atividades, como o sindicalismo e a militância político-partidária. O Jornalismo, nesse caso, representa uma maneira de articular atividade profissional com engajamento político e reconverter recursos militantes para ampliar os espaços de atuação profissional. Tratados em conjunto, os jornalistas apresentaram, durante ou após a militância estudantil, ingresso no Partido dos Trabalhadores (PT) e na esfera sindical, (Central Única dos Trabalhadores (CUT), sindicatos variados, como o Sindicato dos Jornalistas e o Sindicato dos Radialistas, e Federação Nacional dos Jornalistas (Fenaj), ocupando, inclusive, alguns cargos como diretores e presidentes, e trabalhando em campanhas eleitorais na qualidade de jornalistas assessores. As participações políticas e o exercício da militância são, frequientemente, apresentados como inerente ao exercício do Jornalismo, tal como eles concebem-no, ou seja, um Jornalismo de intervenção social e atuação na realidade.

5 Como salientam Gaxie \& Offerlé (1985), o militantismo não só contribui para formação de uma rede de relações possíveis de serem mobilizadas em situações diversas, como predispõe a uma "visão militante do mundo". 
Do conjunto dos casos considerados, destacaram-se a ocupação de "cargos de confiança” na burocracia pública, a realização de campanhas e candidaturas eleitorais e a atuação em movimentos sociais. Dentre os postos, estão os seguintes: direção de rádio estatal, secretaria da comunicação no Estado, assessoria de comunicação para campanhas e candidaturas eleitorais e para movimentos sociais e ONGs. Os convites e indicações para realização de tais atividades partiam dos próprios políticos, na maioria das vezes companheiros de militância partidária ou de colegas jornalistas também membros do partido. Em alguns casos, as duas condições (jornalista e militante do partido) convergiam.

Por conseguinte, os cargos conquistados dependeram das esferas sociais nas quais os jornalistas estavam inseridos e que possibilitaram acumular um conjunto de recursos sociais que permitiram o acesso a certas posições profissionais. Dentre estas esferas sociais, destacaram-se a esfera da política (partidos políticos, neste caso o Partido dos Trabalhadores), a esfera da militância (movimento estudantil e movimentos sociais diversos) e a própria esfera profissional, sobretudo as redações jornalísticas, as quais permitiram estabelecer novos vínculos e estreitar os já existentes, resultando no acesso a posições profissionais. Um exemplo de como isto ocorre pode ser encontrado na trajetória de um dos jornalistas entrevistados. Este jornalista atuou, durante a graduação, no movimento estudantil e, em seguida, na política partidária e sindical, o que lhe permitiu um contato extenso com movimentos sociais e sindicatos. Tal contato resultou no acesso a atividades de assessoria de comunicação tanto para os movimentos como para os partidos políticos. Além disso, seu trabalho jornalístico como repórter destacou-se por meio da cobertura de movimentos sociais diversos, o que lhe possibilitou reforçar ainda mais o contato com os movimentos sociais. Portanto, as militâncias político-partidária e sindical, associadas ao exercício do Jornalismo, fornecem os meios necessários para conquistar certos postos.

Uma das questões que se destaca é que a inserção militante não é vista como algo acidental ou que desvie o militante da sua profissão, mas, ao contrário, é prova de qualidade extraordinária. A militância política é vista como uma aprendizagem e como uma qualificação que fornece um saber especial sobre o social, uma vez 
que o jornalista deve ser um militante em todos os sentidos, que luta não só pela veracidade das informações que produz no interior das redações, como também luta em defesa da sociedade e da democracia. O relato abaixo ilustra tal visão:

"No período que eu trabalhei no jornal, foi o auge das ocupações [de terra] ${ }^{6}$. Daí cobria direto essas matérias (....). Essa área é uma área que eu gosto muito, até pelo fato da minha militância e de tudo isso eu achava que eu cobria bem e eu achava que tinha que cobrir essas coisas. E eu acho melhor quem tem uma visão mais clara em relação a todos os movimentos sociais. Então eu ia direto, não tinha problema nenhum. (...) Quem tem militância política tem muito mais condições, transita bem e consegue explicar bem, fazer bem as matérias de política".

O que caracteriza os trajetos dos jornalistas que nesse padrão encaixam-se é uma diversidade de vínculos sindicais e políticos, obtidos por meio da inserção em partidos políticos. A militância exercida no espaço dos sindicatos e dos partidos políticos possibilita não só uma qualificação especial, um saber sobre o social valorizado entre as lideranças, mas também permite o acesso a certas posições e postos dentro do Jornalismo. Uma dessas posições ocupadas é a de assessor, consultor, diretor, secretário de instituições públicas. $\mathrm{O}$ trabalho de assessoria ou consultoria prestada para campanhas eleitorais, sindicatos, movimentos sociais diversos, bem como o serviço na burocracia pública como secretário de comunicação ou diretor de emissora pública (TVE, por exemplo) é visto como uma forma de exercício profissional pelo conjunto dos jornalistas considerados. A ocupação desses cargos dá-se em nome de uma "competência profissional”. Entretanto, esses postos são conquistados por meio de uma rede de contatos e vínculos políticos que permite associar o exercício da profissão ao exercício de uma atividade política. Além disso, esse tipo de uso do Jornalismo e a combinação entre títulos profissionais e demais títulos obtidos pela inserção militante revela uma atuação polivalente e uma "expansão horizontal"7 da profissão. Essas questões

6 Grifo do autor.

7 Essa expressão é utilizada aqui no sentido atribuído por Coradini (2006) em um dos seus trabalhos sobre o uso de recursos profissionais para fins eleitorais. Ao 
indicam uma das modalidades de utilização do exercício profissional que aparece associado ao exercício do militantismo.

Como se pode perceber, a acumulação de relações sociais está associada às atividades militantes e políticas e como elas complementam-se, assim como na militância estudantil e na partidária, por meio da inserção e da filiação em partidos políticos, de representação categorial, como militância sindical e outros tipos de associativismos. Além dessas inserções, as quais permitem a formação de capital de relações, há também as inserções em espaços como a academia, os jornais e a imprensa de modo geral. Isso quer dizer que a gestão da inserção profissional resulta de uma vasta rede de relações conquistadas que são mobilizadas para ampliar os investimentos profissionais.

Para demonstrar como a esfera política contribui para o ingresso e ascensão profissional tomar-se-á algumas trajetórias como exemplares desta modalidade. Tais trajetórias permitem vislumbrar as condições que fazem com que a militância estudantil, o sindicalismo e a atuação política partidária, tornem-se componentes nas possibilidades de reconversões para o exercício profissional. Cabe destacar que, neste estudo, a comparação entre diferentes trajetórias tornou-se um procedimento importante na medida em que permitiu explicitar certas características gerais e demonstrar que, mesmo dentro de uma modalidade, há arranjos diversos.

Um dos casos exemplares do padrão de trajeto profissional de jornalista e sua vinculação com a esfera política é o caso de um dos secretários da Fenaj, também membro do Fórum Nacional pela Democratização da Comunicação (FNDC), da diretoria do Fórum Nacional de Professores de Jornalismo (FNPJ), da diretoria do Sindicato dos Jornalistas do Rio Grande do Sul e representante no Conselho de Comunicação Social. A relação entre exercício profissional do Jornalismo e da política, neste caso, é intensa, o que lhe permitiu chegar a secretário de comunicação e candidato a deputado federal. Sua

empregar essa expressão, o autor refere-se aos advogados que combinam o seu exercício profissional com outros títulos profissionais, como uma forma de "expansão horizontal” da profissão. Uma das maneiras de ampliar a atuação é por meio das assessorias em diferentes esferas, com destaque para organismos públicos. 
participação política tem início em grupos e movimentos estudantis, com intensa atividade em um grupo chamado Liberdade e Luta $(\text { Libelu) })^{8}$. No centro acadêmico do curso de Arquitetura, primeira faculdade iniciada, disputou, com sucesso, a Presidência do mesmo representando o "movimento camponês, operário, estudantil" da Libelu, concorrendo com outras duas chapas, uma delas era do Partido Comunista (PCB) e a outra da União Democrática Socialista (UDS) ${ }^{9}$. Nessa época, a Libelu disputava o controle de diversos diretórios acadêmicos no país. Sua entrada nesse grupo ocorreu via um colega do movimento estudantil da universidade onde cursava Arquitetura. Na Libelu afirma ter lido livros clássicos do comunismo e do trotskismo: "Líamos e discutíamos Marx, Lênin e Trotski e todos os comunistas", relembra o jornalista. Nestes grupos, estabeleceu relações com colegas que seriam futuros companheiros de militância partidária e de carreira política. A academia foi o primeiro espaço a aparecer ligado às suas preocupações políticas, conectando assim o engajamento político à vida estudantil. Mais tarde, é a sua vida profissional que aparecerá ligada à militância política.

Ao mesmo tempo em que investia na militância e fazia o curso de arquitetura, começou a atuar em jornais diários da capital fazendo charge e na Cooperativa dos Jornalistas (Coojornal), de Porto Alegre (RS), como ilustrador. Depois de já estar inserido nas redações de jornais, decidiu fazer o curso de Jornalismo, onde atuou no diretório acadêmico na qualidade de presidente e intensificou contatos com professores e colegas que estavam atuando nas redações de jornais. Tais contatos renderam-lhe algumas ofertas de emprego. Uma delas ocorreu por intermédio de um colega que o indicou para uma vaga no "Correio do Povo". Nesse momento já fazia algumas charges para esse jornal o que lhe possibilitou acumular duas funções no "Correio do Povo". Logo depois da falência do jornal e da mudança de pro-

8 Representava uma corrente trotskista do movimento estudantil. Formada, principalmente, por estudantes universitários e secundaristas tornou-se uma das principais organizações de articulação do movimento estudantil nos anos 1970. A Libelu nasceu da Organização Socialista Internacional (OSI) e teve como berço a Universidade de São Paulo (USP). Para disputar o diretório acadêmico central da USP alguns integrantes da OSI formaram a chapa Liberdade e Luta. Assim a Libelu tornou-se uma tendência que atraía milhares de estudantes.

9 Criada em 1945, em São Paulo, por socialistas opositores ao PCB. 
prietários, passou a ser contratado como chargista, abandonando a função de diagramador. A outra oferta de emprego ocorreu por intermédio de um professor da faculdade, também colega de redação do jornal "Correio do Povo", que o convidou para dar aulas na PUC, função que desempenha até hoje. Nesse momento, acumulava a função de chargista e de professor universitário, além de intensa atividade política e sindical. Sua atividade sindical, já iniciada desde o momento em que entra para as redações de jornais, intensificase a partir do momento em que é escolhido delegado sindical da redação do "Correio do Povo".

A entrada no sindicato e a militância partidária ocorrem simultaneamente, mas os investimentos em cada um destes espaços, como ocupação de cargos e a ampliação da atuação, acontecem em momentos diferentes da carreira. Quando passa a ocupar cargos dentro do sindicato já tinha um longo percurso dentro do PT. Sua primeira Presidência no sindicato ocorreu em 1989, quando o PT venceu as eleições municipais e toda a diretoria do sindicato dos jornalistas foi convocada para organizar a assessoria de comunicação da prefeitura. Nesse momento, de vice-presidente passa a assumir a função de presidente. Foi diretor do Sindicato dos Jornalistas do Rio Grande do Sul por três gestões. Desse modo, é possível perceber um processo de acumulação e ampliação das esferas de atuação.

O ingresso em um curso de graduação em Jornalismo ocorreu no mesmo período em que rompeu com a Libelu para participar da criação do PT em Porto Alegre. A divergência interna na Libelu sobre a possibilidade de integrar um novo partido fê-lo romper com o grupo e aderir a um "verdadeiro partido operário", como ele mesmo definiu em entrevista. Apesar de continuar na direção de centros acadêmicos é possível perceber uma passagem quase imediata da militância estudantil para a partidária. Esse jornalista começa na militância estudantil, passa a investir no partido e, aos poucos, o movimento estudantil é substituído pelo movimento sindical.

A vida acadêmica desse jornalista, na graduação ou na pósgraduação, tem um sentido de militância permanente. Alguns anos após a conclusão do curso de graduação, em 1984, ingressou no mestrado de sociologia da Universidade Federal do Rio Grande do Sul (UFRGS), curso que não concluiu em função da intensa atividade 
partidária, sindical e profissional nos jornais da capital. A entrada no mestrado foi motivada por um conjunto de amigos, muitos deles do PT, que lá estavam e porque, na sua visão, era um lugar em que se fazia uma leitura sistemática de teoria, possibilitando organizar e sistematizar um debate que fazia ideologicamente na militância. Segundo ele, por meio do curso pode "estudar Marx de uma maneira mais organizada e crítica”. Depois deste mestrado, esse jornalista iniciou o mestrado em Comunicação na UFRGS e, atualmente, está concluindo o mestrado em Comunicação na PUC. Sua experiência de militante estimulou não só sua vida acadêmica como toda sua vida profissional. Nesse sentido, o seu engajamento político tende a estruturar os seus investimentos profissionais.

A entrada no curso de graduação em Jornalismo, segundo ele, representava uma extensão de sua militância. Em função de já estar atuando em jornais e fazendo militância, afirma ter optado pelo curso de Jornalismo para "transformar o país e reformar o mundo", razão pela qual também atua na política e continua no Jornalismo. Ele afirma ainda ter encontrado as motivações necessárias para a entrada no Jornalismo na militância estudantil, a qual permitiu desenvolver, de forma organizada, uma "crítica social" já manifestada na infância e na juventude. A apresentação dos motivos que o levaram a escolher o Jornalismo torna-se um meio apropriado para integrar seus interesses políticos dentro da sua futura vida profissional. A escolha aparece elaborada em ligação com sua sensibilidade política, o que contribui para reforçar ainda mais o seu engajamento.

Além disso, na sua visão, o papel do Jornalismo e do jornalista é intensificar a "esfera pública", proporcionar às populações excluídas e de baixa renda as mesmas informações que são destinadas a outros grupos sociais e não propor jornais especializados, jornais que seriam, em suas palavras, "de classe, segmentados". Desse modo, o jornalista estaria cumprindo o seu papel de contar a história cotidiana a todos os segmentos sociais, selecionando o que é de "interesse público" nessa história, aquilo que interessa à população como um todo. Isso demonstra uma definição militante das próprias competências jornalísticas e a reconversão de saberes incorporados pela experiência política em um "saber-fazer" jornalístico. 
Porém, os significados atribuídos ao passado e ao próprio exercício do Jornalismo dependem da interseção com as esferas às quais estava vinculado. A inserção na militância estudantil, partidária e sindical cria as condições para esta percepção e para a conquista de cargos, ampliando, assim, as esferas de atuação profissional. O militantismo, nesse caso, estudantil, partidário e sindical contribui não só para formação de uma rede de relações, que pode ser mobilizada em diversas situações, mas também para uma visão de mundo militante (GAXIE \& OFFERLÉ, 1985; CORADINI, 2001). Assim, ele orienta subjetivamente as "esferas" de sua "vida" pelos seus engajamentos.

Esse caso representa uma modalidade de associação de recursos em que a atuação partidária e sindical ocorre simultaneamente aos investimentos no Jornalismo, possibilitando uma interferência nesses dois espaços. Os exemplos dessas interferências podem ser encontrados nas diversas greves da categoria do qual participou, nos cargos políticos que ocupou na qualidade de jornalista e na participação na Coojornal, compondo a última chapa (petista) vencedora das eleições na década de 1980, a qual levaria ao racha definitivo da cooperativa. O fim da Coojornal foi provocado por uma forte tensão entre aqueles que representavam o grupo fundador, e que pensavam a cooperativa como um empreendimento jornalístico, e aqueles que pensavam o jornal como um empreendimento político, representado pela chapa formada por militantes do PT.

No que diz respeito aos cargos políticos que ocupou, esse jornalista foi Secretário de Comunicação do governo do estado do Rio Grande do Sul pelo PT. Além desse cargo, candidatou-se a deputado federal pelo PT, reconvertendo assim os recursos políticos em recursos eleitorais, mas, como não se elegeu, o partido convidou-o para administrar a pasta de comunicação do estado.

Atualmente, além de professor, esse jornalista atua na secretaria da Fenaj, na diretoria do Sindicato dos Jornalistas do Rio Grande do Sul, na coordenação do FNDC, compõe a diretoria do FNPJ e representa os jornalistas no Conselho de Comunicação Social. As sucessivas ocupações de posições de lideranças e de cargos em organizações sindicais, associativas e políticas ocorrem simultaneamente ao investimento na carreira acadêmica. Esses postos adquirem um duplo sentido, na medida em que esse jorna- 
lista apresenta-os constantemente como uma atuação profissional e política. Essas atuações, apesar de representarem a ocupação de cargos políticos que dependem de vínculo partidário, são percebidas como atuações jornalísticas que permitem colocar o conhecimento que ele tem do Jornalismo a serviço da comunicação e da política. As atividades políticas são definidas como um prolongamento da atuação profissional e essa última, por sua vez, é percebida como completamente política, visto que o próprio exercício do Jornalismo é concebido como uma atividade militante que implica intervenção e atuação diante da realidade. Os cargos e as atividades que desempenha atualmente, como representante de entidades da categoria e de movimentos sociais como FNDC, dentre todos os outros, representam a possibilidade de desempenhar esse duplo papel, promovendo políticas de comunicação e colocando o conhecimento jornalístico a serviço da população.

Em síntese, esse trajeto caracteriza-se por um conjunto de investimentos simultâneos ao Jornalismo, no Partido dos Trabalhadores e no Sindicato dos Jornalistas do Rio Grande do Sul. Os contatos proporcionados por tais investimentos renderam-lhe uma candidatura e o cargo de secretário estadual de comunicação, além de possibilitarem-lhe a liderança sindical. A inserção militante, partidária e sindical permite acumular um conjunto de recursos que podem ser usados para diversificar os espaços de atuação jornalísticos.

A ligação entre a esfera profissional e aquela do engajamento aparece claramente tanto no que diz respeito aos recursos que são convertidos para ampliar os espaços de atuação profissional, como nos aspectos subjetivos que permitem estabelecer uma conexão entres esses espaços ${ }^{10}$. Ao longo da entrevista realizada para este estudo, ele não cessou em colocar que seu trabalho e seu engajamento político fazem parte de um todo e que não estão separados, apesar de seu constante esforço para controlar as interferências que podem ocorrer entre o Jornalismo e a política. Assim, a imbricação desses espaços dá à sua ação um sentido. Esse jornalista procura apresentar uma coerência em seus relatos entre sua atuação profissional e sua atuação política. A preocupação dessa

10 Para uma visão mais ampla sobre a relação entre esferas de vida, ver Passy, 2005. 
coerência é central para ligar subjetivamente essas esferas que, à primeira vista, não tem laços comuns.

Uma versão mais voltada para o investimento nas assessorias de imprensa é representada por um assessor de imprensa do Ministério da Saúde, atualmente, também componente da diretoria do Núcleo de Assessores de Imprensa do Sindicato dos Jornalistas do Rio Grande do Sul. Natural do interior do estado do Rio Grande do Sul, de uma família com recursos econômicos precários, mãe professora primária e pai operário, ambos membros do Partido Comunista, formou-se em Jornalismo pela PUC em 1985. Durante sua juventude ingressou no Partido Comunista e ali conheceu outros jornalistas que também estavam no partido. Nesse partido ficou até 1995 quando, depois de disputas internas, decidiu ir para o Partido dos Trabalhadores. No período da universidade foi do centro acadêmico do curso de Jornalismo, do diretório acadêmico central e da União Nacional dos Estudantes, momento em que investiu ativamente na militância estudantil e partidária vinculando-se ao Partido Comunista.

Depois de formado, conquistou vaga de jornalista em alguns jornais de Porto Alegre e Florianópolis, sobretudo na editoria de política, investindo concomitantemente em sua militância política. Após alguns anos atuando na editoria de política, seu capital de relações sociais com esse universo era vasto, intensificado ainda mais pela atuação em partidos políticos e militância associativa. Tal capital proporcionou-lhe um convite para atuar na assessoria de imprensa da prefeitura de Porto Alegre, atividade que exerceu durante dois anos e meio. Uma parcela deste período foi exercida concomitantemente a atividade no jornal. Esse emprego foi conquistado por intermédio do prefeito, do PT, que já conhecia o seu trabalho como jornalista de política, mas principalmente já o conhecia da militância partidária. No Jornalismo de redação esse jornalista encontra a possibilidade de reverter seus vínculos em "fontes" e também de ampliar as formas de atuação profissional, não ficando restrito ao universo das redações.

Além da atuação na prefeitura de Porto Alegre, também trabalhou como assessor na Câmara de Vereadores, durante a administração do PT. Seu ingresso nessa atividade ocorreu em função da relação com o universo da política proporcionada pela reportagem política e, também, pela sua atuação sindical e partidária. Na 
Câmara de Vereadores seus contatos ampliaram-se, pois por meio dela conheceu um vereador que se elegeu a deputado estadual e convidou-o para assessorá-lo na Assembléia Legislativa. Mais tarde, quando o PT assumiu o governo do estado do Rio Grande do Sul, em 2000, fez um concurso para assessor na Secretaria de Saúde e foi aprovado. Em seguida foi cedida para o Ministério da Saúde, momento em que a Presidência da República estava com o PT.

Nesse caso, a atividade como repórter de política permitiu e favoreceu o acesso ao universo da política e o contato com políticos por meio da relação com as "fontes", ao mesmo tempo em que esse contato, muitas vezes, era reforçado e intensificado pela sua atuação no Sindicato dos Jornalistas do Rio Grande do Sul e nos partidos nos quais estava vinculado: primeiro o Partido Comunista e, mais tarde, o Partido dos Trabalhadores. Tais inserções reforçavam seus vínculos com a política, não só em função do jornal, mas também em função da atividade militante.

Tal trajeto caracteriza-se pelo investimento concomitante nas redações, nos partidos políticos e no sindicalismo. Isso possibilita inserções diversas no Jornalismo e o acesso aos postos de assessoria de imprensa pública. Dessa forma, é possível perceber as modalidades de existência e as condições de uso da militância (estudantil, sindical, partidária) para ampliação dos espaços de atuação no Jornalismo, assim como os esforços no sentido de converter as relações e os contatos em novas posições. A assessoria de imprensa constitui uma forma particular de reconversão de recursos políticos, muito deles conquistados em função dos contatos com o universo da política proporcionados pela editoria de política, e no universo militante (sindicato, partidos políticos) em novas formas de atuação profissional.

\section{Considerações finais}

Este artigo teve como objetivo principal apresentar um dos principais padrões de ingresso e ascensão no Jornalismo. Tal padrão permite definir a militância política como a principal base de recursos profissionais e, desse modo, ela não é apenas um complemento nas carreiras dos jornalistas, mas é indispensável para compreender suas trajetórias. Em todos os casos apresentados, é possível discer- 
nir alguns mecanismos que criam determinadas condições para a reconversão da liderança política em recurso profissional, tais como militância estudantil associada ao sindicalismo, vínculos com partidos políticos e a atuação profissional no interior das redações. Isso gera um acúmulo de recursos de relações que podem ser mobilizados, a qualquer momento, para o exercício do Jornalismo em setores diversos. A própria trajetória estudantil e profissional confunde-se com os investimentos em lideranças e representações associativas, sindicais e partidárias. A vida estudantil e profissional está relacionada a uma sucessão de postos ocupados na militância estudantil, nos partidos políticos e no sindicato profissional da categoria e um conjunto de esforços no sentido de convertê-las em recursos profissionais e em formas de acesso a posições. Nesse sentido, o Jornalismo apresenta-se como um espaço onde é possível converter as habilidades e os vínculos adquiridos na militância em formas de atuação profissional.

Outra questão que merece ser destacada nessas trajetórias é que a maneira própria de perceber a profissão e de apresentar os motivos para sua escolha está diretamente associada à militância. A militância estudantil, sindical e as inserções em partidos políticos são percebidas como qualidades que permitem uma visão diferenciada da profissão, contribuindo para que o jornalista desempenhe o seu verdadeiro papel de militante da sociedade, defendendo o próprio Jornalismo como um bem público e também lutando em defesa da democracia. A inserção política torna-se uma qualidade, um diferencial para esses jornalistas, na medida em que permite $o$ desenvolvimento de habilidades e competências específicas que são inerentes à atividade jornalística. Portanto, a militância contribui não só para acúmulo de recursos distintos, mas para uma maneira própria de ver o mundo e a própria atividade profissional.

Assim sendo, com base na investigação das trajetórias apresentadas neste texto, é possível perceber que se trata de jornalistas com considerável capital coletivo ${ }^{11}$ e político, para os quais a

11 Entendido aqui, no sentido atribuído por Gaxie e Offerlé (1985), como um conjunto de postos ocupados em instâncias sindicais por agentes situados em associações ou empresas coletivas de representação. Tais postos podem contribuir para acumular crédito suscetível de ser colocado no mercado político. 


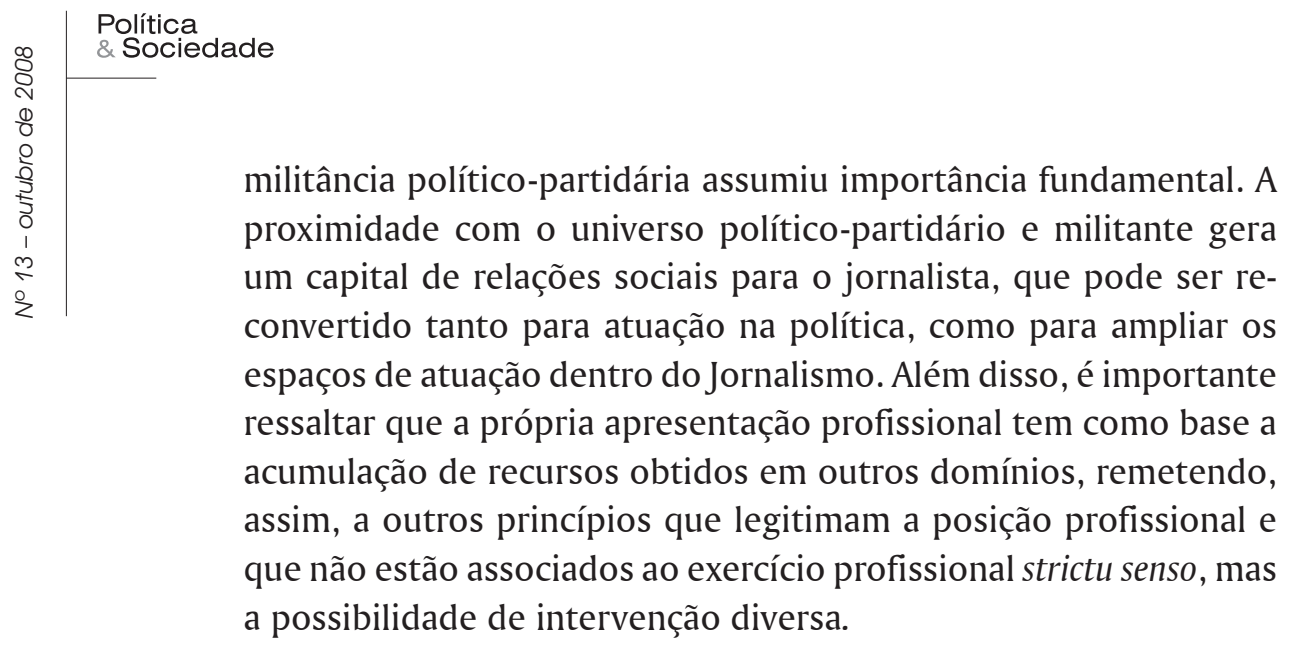

Recebido em 7 de dezembro de 2007 Aprovado em 8 de maio de 2008

\section{Referências}

BOLTANSKI, L. Les Cadres. La formation d'um groupe social. Paris: Minuit, 1982.

BOURDIEU, P. Homo Academicus. Paris: Minuit, 1984.

. As Regras da Arte. São Paulo: C. das Letras, 1996.

CORADINI, L. Em nome de quem? Recursos sociais no recrutamento de elites políticas. Rio de Janeiro: R. Dumará, 2001.

. Relações profissionais e disputas eleitorais. In: BARREIRA, C \& PALMEIRA, M. Política no Brasil. Visões de Antropólogos. Rio de Janeiro: R. Dumará, 2006.

DOGAN, M. Les professions propices à la carrière politique ; osmoses, filières et vivieres. In.: OFFERLÉ, M. (dir.). La profession politique: XIXe. Siècles. Paris: Belin, 1999.

DULONG, D. Quand l'économie devient politique. La conversion de la compétence économique en compétence politique sous la Ve République. Politix, Paris, n. 35, p. 109-135, 1996.

GAXIE, D. Rétributions du Militantisme et paradoxes de l'action colletive. Political Science Review, n. 11, p. 157-188, 2005.

GAXIE, D. \& OFFERLÉ, M. Les militants syndicaux et associatifs au pouvoir? Capital Social Collectif et Carriere Politique. In.: BIRNBAUM, 
Pierre (dir.). Les élites socialistes au pouvir - 1980-1985. Paris: Universitaires de France, 1985.

OFFERLÉ, M. Entrées en politique. Politix, Paris, no 35, p. 3-5, 1996. . Professions et Profession Politique. In.: OFFERLÉ, M. (Dir.). La profession politique: XIXe. Siècles. Paris: Belin, 1999.

RIEFFEL, R. L'élite des journalistes. Paris: Universitaires de France, 1984.

PASSY, F. Interactions sociales et imbrications des sphères de vie. In: FILLIEULE, O. (Org.) Le desengagement militant. Paris: Belin, 2005. SAWICKI, F. 1999. Classer les hommes politiques. Les usages des indicateurs de position sociales pour la compréension de la profissionalisation politique. In: OFFERLÉ, M. (dir.). La profession politique: XIXe. Siècles. Paris: Belin, 1999.

WEBER, M. A política como vocação. Ensaios de sociologia. Rio de Janeiro: Guanabara, 1982.

WILLEMEZ, L. Perseverare diabolicum: l'engagement militant à l'épreuve du vieillissement social. Lien social et politiques- RIAC, 51, Printemps, 2004. 
